\title{
Measuring Burden of Illness in Phenylketonuria (PKU): Development of the PKU Symptom Severity and Impacts Scale as a Robust Patient-Reported Outcome
}

Jennifer Quinn · Alexandros Georgiadis · Hannah B. Lewis •

Elaina Jurecki

Received: August 13, 2021 / Accepted: November 5, 2021 / Published online: December 18, 2021

(C) The Author(s) 2021

\section{ABSTRACT}

Introduction: Phenylketonuria (PKU) is a rare, metabolic genetic disorder that can cause various neuropsychological symptoms that often affect patients' health-related quality of life, even for patients with good metabolic control. To date, no patient-reported outcomes (PRO) instrument combines the measurement of neuropsychological and dietary concepts to capture the broad impact of PKU on quality of life. This article presents the development of the PKU Symptom Severity and Impacts Scale (PKUSSIS), a PRO instrument that is designed to evaluate neuropsychological symptoms and impacts in early-treated patients with PKU.

Methods: A draft instrument was developed based on a targeted literature review, PKU expert physician interviews, and an advisory board consisting of patients with PKU. Qualitative interviews combining concept elicitation/ cognitive interviews were conducted with patients with classic PKU aged at least 15 years

J. Quinn ( $\square)$

BioMarin Europe Ltd, 10 Bloomsbury Way,

London WC1A 2SL, UK

e-mail: jennifer.quinn@bmrn.com

A. Georgiadis - H. B. Lewis

ICON Clinical Research UK Ltd, Buckinghamshire,

UK

E. Jurecki

BioMarin Pharmaceutical Inc, Novato, CA, USA old. A separate sample of 20 patients with PKU completed the draft PKU-SSIS in a paper survey format, to enable preliminary assessment of any floor and ceiling effects.

Results: Patient interviews elicited four key symptom themes: neurocognitive function, emotional and behavioral, physical functioning, and physical health. Four impact themes were also identified: social function, physical health, emotions, and level of independence. No floor or ceiling effects were identified.

Conclusion: The final instrument included 22 items, covering three symptom domains (1. emotional, mood, and psychological; 2 . (neuro)cognitive, executive, and intellectual function; and 3. physical health), and four impact domains (1. social relations, 2 . level of independence, 3 . general well-being, and 4 . selfcare). The PKU-SSIS will help to address an important gap in the evaluation of existing and future treatments for PKU.

Keywords: Phenylketonuria; Patient-reported outcomes; Qualitative; Interviews; Neuropsychological; Health-related quality of life 


\section{Key Summary Points}

Concept elicitation interviews with patients with Phenylketonuria (PKU) on their experience of the condition identified eight themes: symptom themes were (1) neurocognitive function, (2) emotional and behavioral, (3) physical functioning, and (4) physical health; impact themes were (1) social function, (2) physical health, (3) emotions, and (4) level of independence.

The new PKU Symptom Severity and Impacts Scale (PKU-SSIS) enables the measurement of the neuropsychological and physical symptoms and impacts of PKU.

\section{INTRODUCTION}

Phenylketonuria (PKU; OMIM 261600) is a rare genetic metabolic disorder caused by deficient activity of the hepatic enzyme phenylalanine hydroxylase (PAH; OMIM 612349), an essential enzyme for metabolizing the amino acid phenylalanine (Phe) to tyrosine [1]. PKU causes elevated concentrations of Phe in the blood and brain; if untreated, it can cause harmful complications to the growth and function of the brain, including irreversible neurologic impairment during infancy and childhood [2, 3]. In countries with newborn screening programs, PKU is commonly identified soon after birth $[4,5]$, allowing early implementation of treatment and management. Use of a Phe-restricted diet allows for lowering of blood Phe levels, which in turn minimizes and averts severe complications such as neurologic damage (e.g., seizures), severe intellectual deficits, motor abnormalities (e.g., hypertonia, increased reflexes), and psychiatric symptoms [6]. PKU affects on average 1 in every 10,000 births in Europe [7], 1 in every 13,500-19,000 births in the USA [8], and 1 in every 108,823 births in Japan [9].

PKU management has been historically complex, requiring life-long adherence to a Pherestricted diet (i.e., avoiding consumption of high protein food, such as meat, eggs, fish, bread, and milk products), medical food intake (Phe-free amino acid fortified protein supplementation) and/or large neutral amino acids (LNAAs) supplementation, and regular visits to PKU clinics, for metabolic control monitoring via blood samples and food diaries [10]. Treatment adherence is often challenging, particularly from adolescence onwards because of a combination of individual, economic, and social factors [11, 12]. Advances in pharmacological interventions (such as sapropterin dihydrochloride (Kuvan $\left.{ }^{\circledR}\right)$ and pegvaliase-pqpz (Palynziq $\left.{ }^{\circledR}\right)$, BioMarin Pharmaceutical Inc., Novato, CA) have allowed many patients to modify their diet to include a greater natural protein intake, with some able to completely discontinue a Phe-restricted diet and medical nutrition therapy $[13,14]$. Diet non-adherence is a major issue in patients with early-treated PKU (ETPKU) [15, 16], with evidence suggesting that resulting elevated blood Phe levels are directly associated with neuropsychiatric problems (e.g., anxiety, hyperactivity, neurological abnormalities, headaches) [17]. Importantly, patients who discontinue or relax their diet may not recognize their symptoms, or may be unaware that symptoms, such as anxiety or work/family problems, are caused by elevated blood Phe levels, making treatment acceptability and adherence more challenging [12]. Evidence also suggests that even patients with wellcontrolled diets may still be experiencing neuropsychological impairments, such as depression or executive dysfunction [13, 18-20], as target blood Phe levels may still impose toxicities. Compromised metabolic control is also associated with poor health-related quality of life (HRQoL) [21-23].

Given the subjective nature of PKU symptoms (e.g., neuropsychological dysfunction, mood disorders), a patient-reported outcomes (PRO) instrument that collects information directly from patients about symptom severity and impacts is important in clinical studies 
$[24,25]$. However, the measurement of treatment outcomes in patients with PKU is often challenging for several reasons. First, as a result of the heterogeneity of the symptoms, researchers often administer generic PRO instruments [26], or adapt existing PRO instruments $[27,28]$ developed to assess symptoms in other conditions, increasing the risk of not capturing disorder-specific nuances. Second, established tests for measuring psychiatric symptoms can be inadequate for the ETPKU population because of the neurocognitive difficulties they often experience (e.g., lack of expressive language ability and self-awareness) [17]. Third, as a lifelong genetic disease, the symptomatology and HRQoL impact may differ depending on the age and developmental stage [13]. Additionally, the existing PKU diseasespecific PRO instrument (i.e., the PKU Quality of Life instrument) focuses primarily on dietary management and associated impacts [13] and not on neuropsychological symptoms and impacts, failing to capture broadly the experience of patients with ETPKU or any benefit derived from treatments in clinical trials.

The lack of a PRO instrument that sufficiently captures the broad impact of PKU on the quality of life of patients with ETPKU, combining neuropsychological and dietary impacts, presents a challenge in clinical studies when needing to comprehensively evaluate treatment benefit. A new PRO was developed to measure the symptoms and impacts that patients and clinicians find relevant and important in ETPKU. In the PRO development process, meaningful patient and clinician involvement was included, as recommended by the US Food and Drug Administration (FDA) [29].

The aim of this article is to describe the development of a new PRO instrument, the PKU Symptom Severity and Impacts Scale (PKUSSIS), which aims to measure a range of neuropsychological symptoms and impacts relevant and important in patients with ETPKU.

\section{METHODS}

On the basis of a targeted literature review, concept elicitation interviews with PKU clinical experts and an advisory board of patients with PKU, a draft of the PKU-SSIS was developed. The initial draft of the PKU-SSIS consisted of 24 items that assessed various PKU-related symptoms that may result from elevated blood Phe levels over the past 7 days. The draft PKU-SSIS was designed to assess six domains: emotional, cognitive, behavioral, physical functioning, general well-being, and self-care. This study enabled further development of the content and relevance of the PKU-SSIS for patients with ETPKU.

\section{Study Design}

The study used both qualitative and quantitative data collection methods in a sample of patients with classic PKU living in the USA. A sample of 10 patients with PKU, aged at least 15 years old, were recruited for participation in a set of cross-sectional combined concept elicitation/cognitive interviews. An additional sample of 20 adults and adolescents was recruited for the quantitative work, which included only completion of the draft PKU-SSIS. Approval was obtained from Salus Institutional Review Board (Austin, TX, USA). The procedures used in this study adhere to the tenets of the Declaration of Helsinki. Informed consent was obtained from all individual participants included in the study. For adolescent participants, informed consent was obtained from a parent and informed assent was obtained from the participant. Informed consent documents explained that anonymised study results may be used in scientific publications.

\section{Study Population and Eligibility Criteria}

The study team partnered with the National Phenylketonuria Alliance (NPKUA), a PKU Patient Advocacy Organization in the USA, to recruit through their network between February and April 2020. Patients were eligible for the study if they were aged at least 15 and less than 70 years old; were diagnosed with classic PKU (self-reported during screening); could read, write, speak, and understand English fluently; could understand and consider themselves able 
to complete the study procedures as described; and could voluntarily agree to participate by giving written/verbal informed consent. Additionally, members interested in taking part in the interviews had to agree to have the interview audio-recorded to be eligible to participate.

Patients were excluded from the study if they experienced severe cognitive or visual impairment, or hearing difficulty; had taken sapropterin less than 2 weeks prior to screening; had ever taken pegvaliase; or had experienced a psychotic or hypomanic/manic episode less than 2 months prior to study screening.

\section{Data Collection}

Interviewers experienced in qualitative interviewing with patients with cognitive impairments conducted the combined patient concept elicitation/cognitive interviews via telephone. Interviews followed a semi-structured interview guide and were audio-recorded with the participant's permission. For the concept elicitation interviews, the interviewers elicited information on participants' experiences with disease management, symptoms, and impacts on HRQoL associated with PKU. Some of these were spontaneously reported, whereas others were elicited after probing if not previously discussed, to further investigate patients' experiences. For the cognitive interviews, participants completed and reviewed the PKU-SSIS. The interviewers elicited participants' feedback on item interpretation and relevancy, response options, meaningful change, recall period, and the clarity of instructions. The interviews focused on the extent to which the items provided an accurate and complete reflection of patients' experiences with the concepts being measured in the PRO instrument. All participants also completed a socio-demographic and clinical characteristics form. In total, the interviews lasted approximately $90-120 \mathrm{~min}$; to reduce participant burden, participants were given the opportunity to split the interview over more than 1 day. All participants were remunerated for their time. Interviews were audio-recorded and transcribed verbatim. Any personally identifiable information was redacted during transcription.

\section{Data Analysis}

Content and thematic analysis was used for the concept elicitation data [30], using MaxQDA $\odot$ (v11/12) qualitative data analysis software. Two researchers coded each transcript to ensure consistency in the application of codes. Analysis of the concept elicitation data sought to assess and document concept saturation, i.e., the point at which no new concepts emerge from the data, to ensure adequate coverage of the patient experience [31]. A saturation matrix including key concepts was developed to provide evidence for the extent of concept saturation and to give confidence in the sample size. After concept elicitation data analysis, the study team mapped concepts reported by patients to the concepts covered in the PKU-SSIS to identify gaps in the instrument. Content analysis was used for the cognitive interview data using MaxQDA@. This analysis focused on documenting any issues in relation to instrument and item interpretation, relevance, clarity, and comprehension.

For the quantitative analysis $(n=30)$, the PKU-SSIS responses, and the demographic and medical history data, were analyzed descriptively using SAS v9.4. The PKU-SSIS has a 5 -point Likert-type response scale $(0=$ never, 1 = rarely, $\quad 2$ = occasionally, $3=$ frequently, $4=$ very frequently), with items $7,9,10,20,22$, 23 , and 24 being reverse scored. The instrument is scored by calculating the mean of the items scores within each domain, and the total score is the sum of the domain scores. Both domain and total scores are transformed into percentages. If more than $50 \%$ of the items are missing for a domain or the instrument, it is not possible to derive the domain or total score, respectively. Higher scores indicate higher severity of PKU symptoms and their associated impacts, and lower scores indicate lower severity. Data in the demographic and medical history form were summarized using descriptive statistics. 


\section{RESULTS}

\section{Sample Characteristics}

The majority of participants were female $(n=17,56.7 \%)$ and white $(n=29,96.7 \%)$. The age of the patients in the sample ranged from 15 to 56 years old (mean [SD] 34.7 years [10.8]). Table 1 presents the socio-demographic and medical characteristics of the study samples.

\section{Conceptual Model Refinement}

The draft conceptual model was refined upon completion of the concept elicitation interviews. The new conceptual model (Fig. 1) presents the contextual factors, signs and symptoms of PKU, and associated HRQoL impacts. The number and percentage of patients who described each symptom are shown in Table 2. Table 3 presents the PKU conceptual framework.

Participants described symptoms in the following four themes, namely (1) neurocognitive function, (2) emotional and behavioral, (3) physical functioning, and (4) physical health. They also talked about HRQoL impacts in the themes of (1) social function, (2) physical health, (3) emotional, and (4) level of independence.

\section{Neurocognitive Function}

Neurocognitive impairments are key defining symptoms of PKU. These include difficulties with focusing and concentration, thinking clearly, organization and planning, short-term memory, and headaches. Difficulties with focusing and concentration $(n=7,70 \%)$, with thinking clearly $(n=6,60 \%)$, and with organization and planning $(n=6,60 \%)$ were reported by the majority of participants.

More than half of the sample $(n=7)$ reported difficulties with focusing/concentration, meaning inability to focus on a task. Participants reported their symptoms as "being a little spacey" (PKU-4), "feels like this scrambled mess of information in my head" (PKU-1), and "for me to sit and concentrate the entire time does not happen" (PKU-11).
Six participants reported difficulties with thinking clearly (i.e., experiencing difficulties with maintaining attention on anything for too long and muddled thinking). Two participants described the symptom as "PKU brain fog" (PKU-3, PKU-10), explaining that it refers to problems sorting out one's thoughts and being slow to resolve problems. Two participants linked "PKU brain fog" with forgetfulness and difficulties in remembering activities or where they had placed objects. Six participants reported difficulties with organization and planning.

\section{Emotional and Behavioral}

The emotional and behavioral theme describes how the patient interacts with others and related emotions. These include anxiety, irritability, impulsivity, mood swings, depression, difficulty with anger management, lack of ambition, and learning difficulties. Anxiety $(n=9,90 \%)$ and irritability $(n=6,60 \%)$ were reported by the majority of participants.

When asked to describe their experiences with anxiety, participants discussed a range of factors that often made them feel anxious, including social situations, psychological issues (e.g., low self-esteem) and poor disease management. Of the seven participants who were probed, two participants attributed their anxiety to feeling overwhelmed, two talked about financial (in)stability, two discussed work-related issues, and one participant talked about being surrounded by large numbers of people (e.g., social anxiety).

Six participants were asked to describe their experiences with irritability; participants talked about "los[ing] patience" (PKU-3), "having a short fuse, short temper" (PKU-5), and "getting frustrated very, very easily" (PKU-8). Of the four participants who were probed about triggers, one participant reported elevated blood Phe levels and experiencing confrontation from others, one said stress load, and one linked being irritable with being in situations where he can easily lose patience and elevated Phe levels.

\section{Physical Functioning}

The physical functioning theme consists of fatigue/low energy $(n=8,80 \%)$. When asked to 
Table 1 Socio-demographic and clinical characteristics of the sample per study

\begin{tabular}{|c|c|c|c|}
\hline Characteristic & Qualitative study $(N=10)$ & Quantitative study $(N=20)$ & Total $(N=30)$ \\
\hline Gender [female; $n(\%)]$ & $7(70.0 \%)$ & $10(50.0 \%)$ & $17(56.7 \%)$ \\
\hline Age $[$ mean $(S D)]$ & $37.1(10.4)$ & $33.5(11.1)$ & $34.7(10.8)$ \\
\hline \multicolumn{4}{|l|}{ Race, $n(\%)$} \\
\hline White & $10(100.0 \%)$ & $19(95.0 \%)$ & $29(96.7 \%)$ \\
\hline Other (Filipino American) & 0 & $1(5.0 \%)$ & $1(3.3 \%)$ \\
\hline \multicolumn{4}{|l|}{ Working status, $n$ (\%) } \\
\hline Working full-time ${ }^{a}$ & $4(40.0 \%)$ & $5(25.0 \%)$ & $9(30.0 \%)$ \\
\hline Working part-time ${ }^{\mathrm{b}}$ & $3(30.0 \%)$ & $5(25.0 \%)$ & $8(26.7 \%)$ \\
\hline Student & 0 & $3(15.0 \%)$ & $3(10.0 \%)$ \\
\hline Looking after home/family & 0 & $3(15.0 \%)$ & $3(10.0 \%)$ \\
\hline Permanently unemployed & $2(20.0 \%)$ & $1(5.0 \%)$ & $3(10.0 \%)$ \\
\hline Unemployed_seeking work & 0 & $1(5.0 \%)$ & $1(3.3 \%)$ \\
\hline Temporarily unemployed & 0 & $1(5.0 \%)$ & $1(3.3 \%)$ \\
\hline Other $^{c}$ & 0 & $1(5.0 \%)$ & $1(3.3 \%)$ \\
\hline \multicolumn{4}{|l|}{ Education, $n(\%)$} \\
\hline 4-year degree & $3(30.0 \%)$ & $7(35.0 \%)$ & $10(33.3 \%)$ \\
\hline 2-year degree & $3(30.0 \%)$ & $4(20.0 \%)$ & $7(23.3 \%)$ \\
\hline Some college & $4(40.0 \%)$ & $2(10.0 \%)$ & $6(20.0 \%)$ \\
\hline Other $^{\mathrm{d}}$ & 0 & $4(20.0 \%)$ & $4(13.3 \%)$ \\
\hline High school or GED & 0 & $1(5.0 \%)$ & $1(3.3 \%)$ \\
\hline Master's degree & 0 & $1(5.0 \%)$ & $1(3.3 \%)$ \\
\hline Doctoral degree & 0 & $1(5.0 \%)$ & $1(3.3 \%)$ \\
\hline \multicolumn{4}{|l|}{ Marital status, $n(\%)$} \\
\hline Married & $3(30.0 \%)$ & $11(55.0 \%)$ & $14(46.7 \%)$ \\
\hline Single & $4(40.0 \%)$ & $5(25.0 \%)$ & $9(30.0 \%)$ \\
\hline Divorced & $2(20.0 \%)$ & $1(5.0 \%)$ & $3(10.0 \%)$ \\
\hline Widowed & $1(10.0 \%)$ & $1(5.0 \%)$ & $2(6.7 \%)$ \\
\hline Not answered & 0 & $2(10.0 \%)$ & $2(6.7 \%)$ \\
\hline \multicolumn{4}{|c|}{ Current Phe levels $(\mu \mathrm{mol} / \mathrm{L}), n(\%)$} \\
\hline$<120$ & $1(10.0 \%)$ & 0 & $1(3.3 \%)$ \\
\hline $120-360$ & $3(30.0 \%)$ & $2(10.0 \%)$ & $5(16.7 \%)$ \\
\hline $360-600$ & $1(10.0 \%)$ & $1(5.0 \%)$ & $2(6.7 \%)$ \\
\hline $600-1200$ & $4(40.0 \%)$ & $5(25.0 \%)$ & $9(30.0 \%)$ \\
\hline
\end{tabular}


Table 1 continued

\begin{tabular}{|c|c|c|c|}
\hline Characteristic & Qualitative study $(N=10)$ & Quantitative study $(N=20)$ & Total $(N=30)$ \\
\hline$>1200$ & 0 & $1(5.0 \%)$ & $1(3.3 \%)$ \\
\hline Unknown & $1(10.0 \%)$ & $9(45.0 \%)$ & $10(33.3 \%)$ \\
\hline Not answered & 0 & $2(10.0 \%)$ & $2(6.7 \%)$ \\
\hline \multicolumn{4}{|l|}{ Current treatment plan, $n(\%)$} \\
\hline Diet & $7(70.0 \%)$ & $15(75.0 \%)$ & $22(73.3 \%)$ \\
\hline Medical food & $8(80.0 \%)$ & $9(45.0 \%)$ & $17(56.6 \%)$ \\
\hline Special low protein food & $4(40.0 \%)$ & $7(35.0 \%)$ & $11(36.7 \%)$ \\
\hline LNAA & $4(40.0 \%)$ & $1(5.0 \%)$ & $5(16.7 \%)$ \\
\hline Other $^{e}$ & $2(20.0 \%)$ & $1(5.0 \%)$ & $3(10.0 \%)$ \\
\hline None of the above & 0 & $3(15.0 \%)$ & $3(10.0 \%)$ \\
\hline Other medications [Yes, $n$ (\%)] & $8(80.0 \%)$ & $9(45.0 \%)$ & $17(56.7 \%)$ \\
\hline Depression & $3(30.0 \%)$ & $1(5.0 \%)$ & $4(13.3 \%)$ \\
\hline Allergies & $1(10.0 \%)$ & $2(10.0 \%)$ & $3(10.0 \%)$ \\
\hline Asthma & $1(10.0 \%)$ & $2(10.0 \%)$ & $3(10.0 \%)$ \\
\hline Birth control & $1(10.0 \%)$ & $2(10.0 \%)$ & $3(10.0 \%)$ \\
\hline High blood pressure & $1(10.0 \%)$ & $2(10.0 \%)$ & $3(10.0 \%)$ \\
\hline Migraines & $3(30.0 \%)$ & 0 & $3(10.0 \%)$ \\
\hline Anxiety & $1(10.0 \%)$ & $1(5.0 \%)$ & $2(6.7 \%)$ \\
\hline OCD & $1(10.0 \%)$ & $1(5.0 \%)$ & $2(6.7 \%)$ \\
\hline Seizures & $2(20.0 \%)$ & 0 & $2(6.7 \%)$ \\
\hline Heartburn & 0 & $1(5.0 \%)$ & $1(3.3 \%)$ \\
\hline HIV preventative & 0 & $1(5.0 \%)$ & $1(3.3 \%)$ \\
\hline Bipolar disorder & 0 & $1(5.0 \%)$ & $1(3.3 \%)$ \\
\hline Hemorrhoids & 0 & $1(5.0 \%)$ & $1(3.3 \%)$ \\
\hline Osteoarthritis & 0 & $1(5.0 \%)$ & $1(3.3 \%)$ \\
\hline Personality disorder & 0 & $1(5.0 \%)$ & $1(3.3 \%)$ \\
\hline Selective IGM & 0 & $1(5.0 \%)$ & $1(3.3 \%)$ \\
\hline $\mathrm{ADHD}$ & 0 & $1(5.0 \%)$ & $1(3.3 \%)$ \\
\hline Panic disorder & 0 & $1(5.0 \%)$ & $1(3.3 \%)$ \\
\hline Eczema & 0 & $1(5.0 \%)$ & $1(3.3 \%)$ \\
\hline Nutritional deficiencies & 0 & $1(5.0 \%)$ & $1(3.3 \%)$ \\
\hline Heavy metal toxicity & 0 & $1(5.0 \%)$ & $1(3.3 \%)$ \\
\hline
\end{tabular}


Table 1 continued

\begin{tabular}{llll}
\hline Characteristic & Qualitative study $(\boldsymbol{N}=\mathbf{1 0})$ & Quantitative study $(\boldsymbol{N}=\mathbf{2 0})$ & Total $(\boldsymbol{N}=\mathbf{3 0})$ \\
\hline Hormonal imbalance & 0 & $1(5.0 \%)$ & $1(3.3 \%)$ \\
Parkinson's disease & 0 & $1(5.0 \%)$ & $1(3.3 \%)$ \\
Polycystic ovary syndrome & 0 & $1(5.0 \%)$ & $1(3.3 \%)$ \\
Lack of sleep & $1(10.0 \%)$ & 0 & $1(3.3 \%)$ \\
Constipation & $1(10.0 \%)$ & 0 & $1(3.3 \%)$ \\
Angina & $1(10.0 \%)$ & 0 & $1(3.3 \%)$ \\
Gout & $1(10.0 \%)$ & 0 & $1(3.3 \%)$ \\
Seizures & $1(10.0 \%)$ & 0 & $1(3.3 \%)$ \\
Ulcerative colitis & $1(10.0 \%)$ & 0 & $1(3.3 \%)$ \\
Heart disease & $1(10.0 \%)$ & 0 & $1(3.3 \%)$ \\
\hline
\end{tabular}

$A D H D$ attention deficit hyperactivity disorder, GED general educational development, IGM immunoglobulin M, LNAA large neutral amino acids, $O C D$ obsessive compulsive disorder, $S D$ standard deviation

${ }^{a}$ One participant indicated both working part-time and being a student

${ }^{\mathrm{b}}$ One participant indicated working both full-time and part-time in separate jobs

"One participant selected "other" as they were temporarily unemployed because of the COVID-19 pandemic

${ }^{\mathrm{d}}$ Four participants did not select educational categories (one had a 4-year degree and multiple registered nursing certification; one had a technical/medical degree; and two were students in 8th and 9th grade, respectively)

${ }^{\mathrm{e}}$ One participant reported taking L-thyroxine, and another participant reported being on a diet, low protein food, and LNAA. One participant did not specify type of PKU treatment

describe their experiences with fatigue/low energy, participants described the symptom as "intense" (PKU-8), "exhausting" (PKU-1), or "extreme tiredness" (PKU-3). Of the five participants who were probed about triggers, three participants linked the symptom to elevated Phe levels, and two could not attribute it to any specific factor.

\section{Physical Health}

The physical health theme includes headaches, difficulties with sleeping, skin problems, gastrointestinal issues, joint pain, sight problems, bad body odor, frequent hunger, slow healing of wounds, problems with taking medication, feeling sluggish, tremors, and tinnitus. Headaches $(n=9,90 \%)$, difficulties with sleeping $(n=8,80 \%)$, skin problems $(n=6,60 \%)$, and tremors $(n=5,50 \%)$ were reported by the majority of participants.
Of the nine participants who reported headaches as a symptom, four participants reported experiencing headaches several times per month, three said that they were not experiencing headaches very often, and two did not specify, reporting "every now and then" (PKU-7) and "mostly if I get hungry" (PKU-4). Of the six participants who were asked about triggers, two participants attributed their headaches to elevated blood Phe levels, two to stress, and one to the presence of certain smells (e.g., cigar smoke).

When asked to describe their sleeping difficulties, some participants reported having trouble falling asleep, another described difficulty staying asleep, and others reported difficulty going back to sleep. When probed, four participants were asked about the triggers of their sleeping difficulties; two participants said 


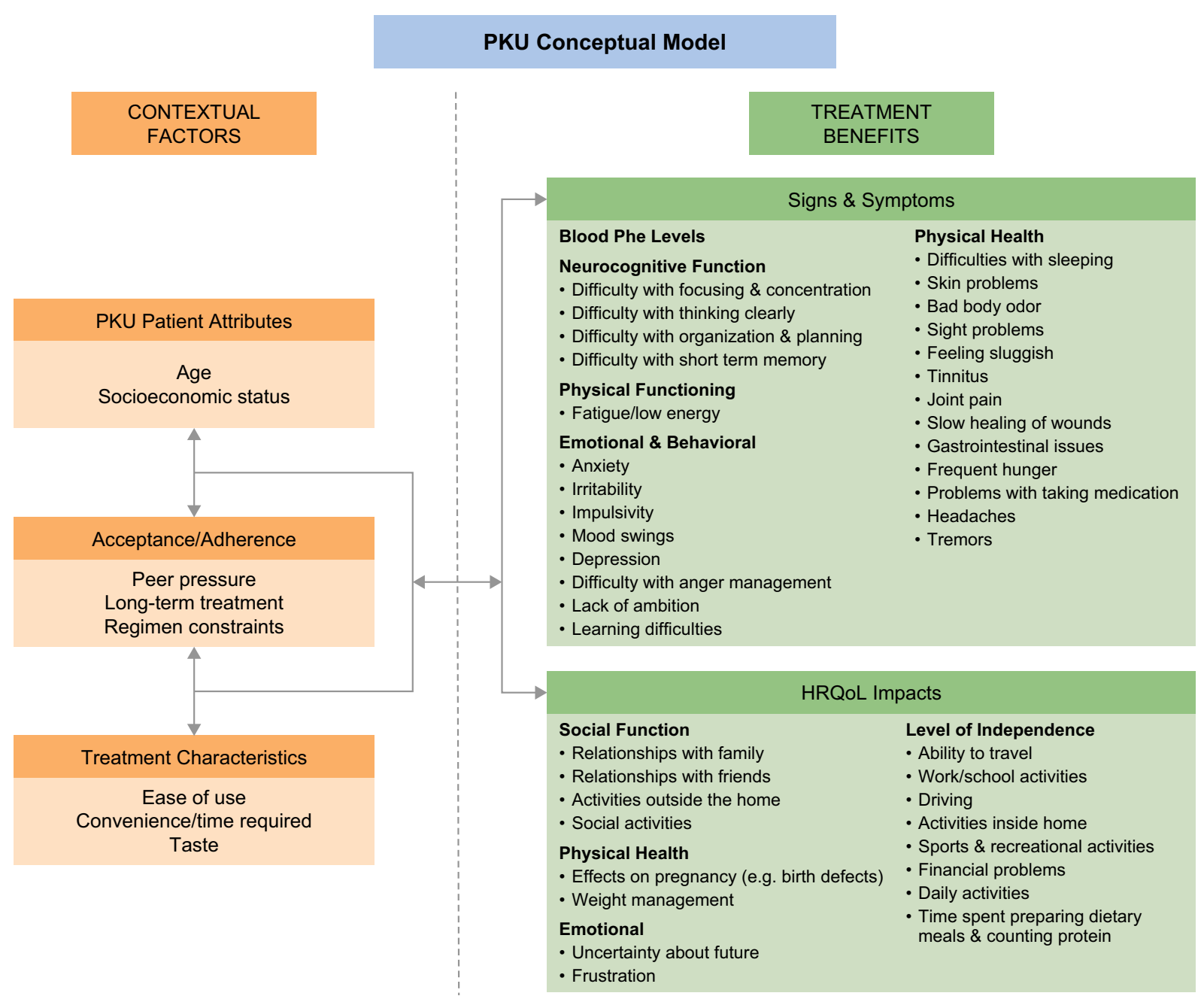

Fig. 1 PKU conceptual model

that overthinking was often a trigger, and one described pain (in his limbs) as a trigger.

When asked to describe the skin problems they experienced, three participants talked about "dry skin" (PKU-2, PKU-5, PKU-10), one about "getting hives or rashes" (PKU-11), one about "having sensitive skin" (PKU-6), and one about having "eczema" (PKU-6). Five participants reported experiencing tremors, including two spontaneous reports. Participants gave different descriptions of their experience with tremors; for example, one participant reported "slight tremors" (PKU-4) in their hands, while another reported experiencing "muscle spasms"
(PKU-10). Three participants linked tremors to elevated blood Phe levels.

\section{Patient Impacts}

Participants reported multiple HRQoL impacts including on social function, physical health, emotions, and level of independence (Table 4). Participants reported their sense of independence being impacted, as they often faced difficulties with a range of activities, including travelling $(n=9,90 \%)$, daily activities $(n=5$, $50 \%)$, performing work/school activities $(n=5$, $50 \%)$ and sports and recreational activities $(n=2,20 \%)$ and driving $(n=3,30 \%)$. Financial difficulties $(n=6,60 \%)$, mainly due to the cost 
Table 2 Summary of spontaneously reported and probed symptoms

\begin{tabular}{|c|c|c|c|}
\hline Symptoms & Spontaneously reported $n(\%)$ & Probed $^{\mathbf{b}} n(\%)$ & Total report $n(\%)$ \\
\hline Anxiety $^{a}$ & $2(20.0 \%)$ & $7(70.0 \%)$ & $9(90.0 \%)$ \\
\hline Headaches $^{\mathrm{a}}$ & $5(50.0 \%)$ & $4(40.0 \%)$ & $9(90.0 \%)$ \\
\hline Difficulties with sleeping $^{a}$ & 0 & $8(80.0 \%)$ & $8(80.0 \%)$ \\
\hline Fatigue/low energy ${ }^{a}$ & $4(40.0 \%)$ & $4(40.0 \%)$ & $8(80.0 \%)$ \\
\hline Difficulty focusing/concentration ${ }^{a}$ & $2(20.0 \%)$ & $5(50.0 \%)$ & $7(70.0 \%)$ \\
\hline Irritability $^{\mathrm{a}}$ & $4(40.0 \%)$ & $2(20.0 \%)$ & $6(60.0 \%)$ \\
\hline Skin problems ${ }^{\mathrm{a}}$ & $1(10.0 \%)$ & $5(50.0 \%)$ & $6(60.0 \%)$ \\
\hline Difficulties with thinking clearly ${ }^{a}$ & $3(30.0 \%)$ & $3(30.0 \%)$ & $6(60.0 \%)$ \\
\hline Difficulties with organization/planning ${ }^{a}$ & $1(10.0 \%)$ & $5(50.0 \%)$ & $6(60.0 \%)$ \\
\hline Tremors $^{\mathrm{a}}$ & $2(20.0 \%)$ & $3(30.0 \%)$ & $5(50.0 \%)$ \\
\hline Impulsivity $^{\mathrm{a}}$ & 0 & $4(40.0 \%)$ & $4(40.0 \%)$ \\
\hline Mood swings ${ }^{a}$ & $1(10.0 \%)$ & $3(30.0 \%)$ & $4(40.0 \%)$ \\
\hline Depression $^{a}$ & $1(10.0 \%)$ & $3(30.0 \%)$ & $4(40.0 \%)$ \\
\hline Difficulties with short-term memory ${ }^{a}$ & $4(40.0 \%)$ & 0 & $4(40.0 \%)$ \\
\hline Difficulties with anger management ${ }^{a}$ & 0 & $2(20.0 \%)$ & $2(20.0 \%)$ \\
\hline Gastrointestinal issues & $1(10.0 \%)$ & 0 & $1(10.0 \%)$ \\
\hline Slow healing of wounds & $1(10.0 \%)$ & 0 & $1(10.0 \%)$ \\
\hline Problems with taking medication & $1(10.0 \%)$ & 0 & $1(10.0 \%)$ \\
\hline Cannot gain muscles & $1(10.0 \%)$ & 0 & $1(10.0 \%)$ \\
\hline Learning difficulties & $1(10.0 \%)$ & 0 & $1(10.0 \%)$ \\
\hline Lack of ambition & $1(10.0 \%)$ & 0 & $1(10.0 \%)$ \\
\hline Frequent hunger & $1(10.0 \%)$ & 0 & $1(10.0 \%)$ \\
\hline Joint pain & $1(10.0 \%)$ & 0 & $1(10.0 \%)$ \\
\hline Tinnitus & $1(10.0 \%)$ & 0 & $1(10.0 \%)$ \\
\hline Sight problems & $1(10.0 \%)$ & 0 & $1(10.0 \%)$ \\
\hline Bad body odor & $1(10.0 \%)$ & 0 & $1(10.0 \%)$ \\
\hline Sluggish & $1(10.0 \%)$ & 0 & $1(10.0 \%)$ \\
\hline
\end{tabular}

${ }^{a}$ Symptom was specifically probed for during the interviews. Difficulties with self-care was also a probed symptom, but no participants reported this either spontaneously or probed; therefore, this symptom has not been not included in the results ${ }^{b}$ If a participant mentioned a symptom spontaneously before probing and talked about it after probing, the mention was counted as spontaneous only 
Table 3 PKU conceptual framework

\begin{tabular}{|c|c|c|}
\hline Concepts & Sub-concepts & Example quote \\
\hline \multicolumn{3}{|l|}{ Symptoms } \\
\hline \multirow[t]{4}{*}{$\begin{array}{l}\text { Neurocognitive } \\
\text { function }\end{array}$} & $\begin{array}{l}\text { Difficulty with focusing and } \\
\text { concentration }\end{array}$ & $\begin{array}{l}\text { "Only when my levels are high... If my levels are normal, I'm laser. I'm not trying to brag or } \\
\text { anything. I mean, I can do this, I can do that. I can do two or three different things at one time } \\
\text { and still have a conversation." (PKU-7) }\end{array}$ \\
\hline & Difficulty with thinking clearly & $\begin{array}{l}\text { "Brain fog is more of like you kind of have a difficult time sorting your thoughts. You really feel like } \\
\text { you're not thinking fast enough or quick enough. You just have a more difficult time } \\
\text { concentrating on a task at hand." (PKU-10) }\end{array}$ \\
\hline & $\begin{array}{l}\text { Difficulty with organization \& } \\
\text { planning }\end{array}$ & $\begin{array}{l}\text { "That's really the big one. I had a boss once say, "Oh, you're horrible with time." He wasn't that } \\
\text { mean about it. He was like, "We need to work on your time management." (PKU-7) }\end{array}$ \\
\hline & $\begin{array}{l}\text { Difficulty with short-term } \\
\text { memory }\end{array}$ & $\begin{array}{l}\text { “...trying to recall information that somebody told me two weeks ago or something I read two } \\
\text { weeks ago, or something like that, I won't be able to do that. The memory recall is a concern." } \\
\text { (PKU-2) }\end{array}$ \\
\hline \multirow[t]{8}{*}{$\begin{array}{l}\text { Emotional and } \\
\text { behavioral }\end{array}$} & Anxiety & $\begin{array}{l}\text { "Now, most of the time there's a few different ways that can happen [anxiety]. One would be } \\
\text { because of my diet. The other is because if I'm describing something about work or something } \\
\text { I'm passionate about, I get really focused and really intense." (PKU-3) }\end{array}$ \\
\hline & Irritability & $\begin{array}{l}\text { “Oh, I wouldn't say it's } 100 \text { percent all of the time, because my levels aren't always high. For } \\
\text { example, like now you asked me what my highest-my last level was, and I told you that was very } \\
\text { high. At that time I was experiencing that irritability." (PKU-3) }\end{array}$ \\
\hline & Impulsivity & $\begin{array}{l}\text { "People get annoyed with me so that's not great, but it's, yeah, it's not earth shattering but yes, I get } \\
\text { annoyed with myself and people get annoyed with me when I can't make a decision and when I } \\
\text { need to talk things out and so yeah, it does impact my life and my relationships." (PKU-5) }\end{array}$ \\
\hline & Mood swings & $\begin{array}{l}\text { "When I'm moody, like I said, I have to seclude myself, and I'm a people person. I love to be around } \\
\text { people, so that bugs me a lot." (PKU-1) }\end{array}$ \\
\hline & Depression & $\begin{array}{l}\text { "I don't really recognize a depression because that's kind of how I've felt all my life. When I went in } \\
\text { to talk to my doctor, which is the last time I was put on meds for it, it felt like it may be a } \\
\text { circumstantial thing. I had some things go on that I felt like maybe sent me into a deeper } \\
\text { depression." (PKU-1) }\end{array}$ \\
\hline & $\begin{array}{l}\text { Difficulty with anger } \\
\text { management }\end{array}$ & $\begin{array}{l}\text { "I was starting to have like within a span of two months I had two totally irrational angry outbursts } \\
\text { at things that were pretty mundane or like not, maybe not mundane but just like not, didn't } \\
\text { require that level of heightened anxiety and anger." (PKU-4) }\end{array}$ \\
\hline & Lack of ambition & $\begin{array}{l}\text { "There's just very little drive to get anything done or to pick up your challenges or so see current } \\
\text { challenges through. It is actually a lot like having the flu. I feel like I've been hit by Mack truck } \\
\text { and I no desire to get up." (PKU-8) }\end{array}$ \\
\hline & Learning difficulties & $\begin{array}{l}\text { "I have some learning. I was in college this year, and I had to get like some special help, and I had to } \\
\text { get this psychological evaluation done, and I have some learning disabilities that they think could } \\
\text { be from PKU. I don't comprehend things the way that other people comprehend things, so } \\
\text { sometimes people have to tell me what to do or like how to do things two or three times before } \\
\text { it's going to click for me." (PKU-11) }\end{array}$ \\
\hline
\end{tabular}


Table 3 continued

\begin{tabular}{|c|c|c|}
\hline Concepts & Sub-concepts & Example quote \\
\hline \multirow[t]{13}{*}{ Physical health } & Difficulties with sleeping & $\begin{array}{l}\text { "It makes it hard to do things because I feel like I haven't slept at all even though I did. It was just } \\
\text { like a really restless sleep, so it feels like I haven't slept all day. Then I'm just very lethargic. I have } \\
\text { literally no energy. I just want to drink coffee all day, times daily." (PKU-11) }\end{array}$ \\
\hline & Skin problems & $\begin{array}{l}\text { "I mean, the ones around my ankles don't really affect me. Well, they are itchy sometimes but they } \\
\text { don't really affect me. The ones behind my ears on my scalp, ugh, those would drive me insane." } \\
\text { (PKU-5) }\end{array}$ \\
\hline & Bad body odor & $\begin{array}{l}\text { "Any PKU patient has, especially people who have been off diet for so long and everything else, } \\
\text { PKU, in general, is a chemical reaction in the body. It's a chemical problem. Part of having the } \\
\text { high Phe in the body, or in the blood, also permeates through the skin. The odor permeates } \\
\text { through the skin. It's like a old musty, warn out, cloven type of thing, an old musty odor that } \\
\text { people experience." (PKU-2) }\end{array}$ \\
\hline & Sight problems & $\begin{array}{l}\text { "I've experienced floaters. There's a lot of different things that as far as I'm talking eye floaters, } \\
\text { floaters in the eyes." (PKU-2) }\end{array}$ \\
\hline & Feeling sluggish & $\begin{array}{l}\text { "I think it's sluggish, almost like a slow—almost like I can't get going. I have a hard time—and that } \\
\text { also might have to do with the executive functioning too, as getting to be able to start, just } \\
\text { starting something. Sometimes I might be more tired." (PKU-10) }\end{array}$ \\
\hline & Tinnitus & $\begin{array}{l}\text { "I have tinnitus in the ears, and I have a constant ringing in the ears. Just because you aggravate it, } \\
\text { now, maybe, I don't know, but I haven't really known the difference, you know. It's a constant } \\
\text { ringing, every single day, in my head." (PKU-2) }\end{array}$ \\
\hline & Joint pain & $\begin{array}{l}\text { "I was working retail, so I was on my feet } 40 \mathrm{~h} \text { a week and I assumed that was the problem, but I } \\
\text { was curious if PKU or any kind of absorption metabolic issue might affect that, worsen it, hasten } \\
\text { it. It's hard to say." (PKU-8) }\end{array}$ \\
\hline & Slow healing of wounds & $\begin{array}{l}\text { "I do not heal at the rate of a normal person. It takes me twice as long to heal as it normally should." } \\
\text { (PKU-11) }\end{array}$ \\
\hline & Gastrointestinal issues & $\begin{array}{l}\text { "We have a lot of issues with constipation in our community, a lot of-I think a lot of it has to do } \\
\text { with the formula intake and the foods that we eat and then stomach upset, a lot of stomach } \\
\text { upset." (PKU-10) }\end{array}$ \\
\hline & Frequent hunger & $\begin{array}{l}\text { “I'm hungry all the time, because I don't eat anything with really high protein. Nothing has really } \\
\text { good satiety. I can eat my carbs and my fruits and veggies and fill up, and then } 15 \text { min later, I'm } \\
\text { looking for something else." (PKU-8) }\end{array}$ \\
\hline & $\begin{array}{l}\text { Problems with taking } \\
\text { medication }\end{array}$ & $\begin{array}{l}\text { "My body, for some reason, doesn't know how to break them down, so I have to be careful with } \\
\text { medications that I take. I don't know." (PKU-11) }\end{array}$ \\
\hline & Headaches & $\begin{array}{l}\text { "I would say I've experienced like what people call the PKU headache where it's sort of like a cloudy } \\
\text { frustrated feeling in the front of your head." (PKU-4) }\end{array}$ \\
\hline & Tremors & $\begin{array}{l}\text { "She [nurse] will have me hold my hands out in front of her and see if they are shaking. Of course, } \\
\text { the higher my Phe level, the more they tremble." (PKU-3) }\end{array}$ \\
\hline $\begin{array}{l}\text { Physical } \\
\text { functioning }\end{array}$ & Fatigue/low energy & $\begin{array}{l}\text { “Maybe just feeling like I didn't get enough sleep the night before or yeah, being kind of lazy and } \\
\text { lethargic. I don't know if that's just, yeah, I can't tell if that's just who I am or it's not a symptom } \\
\text { or not. But yeah, I think in general, I can be lethargic at times." (PKU-5) }\end{array}$ \\
\hline
\end{tabular}


Table 3 continued

\begin{tabular}{|c|c|c|}
\hline Concepts & Sub-concepts & Example quote \\
\hline \multicolumn{3}{|l|}{ Impacts } \\
\hline \multirow[t]{4}{*}{ Social function } & Relationships with family & $\begin{array}{l}\text { "If I eat normal I was between } 2 \text { and } 6 \text { all of the time, anybody can still get irritable. That's just } \\
\text { nature. But mine is completely out of ordinary-out of my persona. I know, and people have } \\
\text { called me out on it, especially my family members. You know, like my wife, my mother, my } \\
\text { father. If I go off and I just lose my mind for a minute and start getting frustrated." (PKU-1) }\end{array}$ \\
\hline & Relationships with friends & $\begin{array}{l}\text { “The migraines affect me being able to have real solid friendships. I don't tend to make really close } \\
\text { friends. I have, like, just acquaintances that are friendly, I guess, but I don't really have real close } \\
\text { friends just because I don't have time to spend with them. I'm, typically, down and out with a } \\
\text { migraine or just too tired to want to do anything or spend any time with anybody. I desire that. I } \\
\text { desire to have a close friend or two. I just can't make the friendship happen, if that makes sense.” } \\
\text { (PKU-1) }\end{array}$ \\
\hline & Activities outside the home & $\begin{array}{l}\text { "We always have to make sure we have a cooler, because our formulas have to be cold, and then } \\
\text { yeah, I think that's really it." (PKU-10) }\end{array}$ \\
\hline & Social activities & $\begin{array}{l}\text { "If it's a social activity, going out to eat or eating with friends at their places, it could be a problem." } \\
\text { (PKU-11) }\end{array}$ \\
\hline \multirow[t]{2}{*}{ Physical health } & Effects on pregnancy & $\begin{array}{l}\text { "Especially in the case of pregnancy, like I mentioned, that damage is not exclusive to you. There is a } \\
\text { massive liability to affect the people around you with the choices you make about your own } \\
\text { health, which is probably true for most everybody, but in a way that's a little more readily } \\
\text { apparent when you have something like PKU.' (PKU-8) }\end{array}$ \\
\hline & Weight management & $\begin{array}{l}\text { "The only the thing I don't think I specifically spoke on was weight management, which is pretty } \\
\text { self-explanatory. It's a diet that's high in sugar and fat and starch. Too, I know I talked about } \\
\text { trying to balance Phe against general nutritional health, and weight is a big part of that and is } \\
\text { only getting worse as I get older, especially as I look at looming pregnancy." (PKU-8) }\end{array}$ \\
\hline \multirow[t]{2}{*}{ Emotional } & Uncertainty about future & $\begin{array}{l}\text { "I have no idea what that's going to look like for me. There is very little information on aging with } \\
\text { PKU with a controlled diet." (PKU-8) }\end{array}$ \\
\hline & Frustration & $\begin{array}{l}\text { "I think just being frustrated by it all the time. If I didn't have the frustration and the separation, I } \\
\text { think, in general, I would have a better quality of life." (PKU-1) }\end{array}$ \\
\hline
\end{tabular}


Table 3 continued

\begin{tabular}{|c|c|c|}
\hline Concepts & Sub-concepts & Example quote \\
\hline \multirow[t]{8}{*}{$\begin{array}{l}\text { Level of } \\
\text { independence }\end{array}$} & Ability to travel & $\begin{array}{l}\text { "That it's hard to go traveling with because when I travel, I have to come up with, and I have to call } \\
\text { my doctors, have traveling papers, trying to get through customs with formula is just a pain } \\
\text { because they're always stopping you. I've had so many problems traveling internationally and } \\
\text { even in the states with formula." (PKU-11) }\end{array}$ \\
\hline & Work/school activities & $\begin{array}{l}\text { "I will actually meet with the principal more to make sure that I'm doing what I need to do. I think } \\
\text { what's kind of nice about being a special education teacher is I already know what supports I } \\
\text { need in place to help with executive functioning and different tools you can use. So I'll do lots of } \\
\text { check lists or reminders. I have the sticky notes. I have a timer on." (PKU-10) }\end{array}$ \\
\hline & Driving & $\begin{array}{l}\text { "I would get lightheaded just driving down the road. Everything would spin, and it was causing } \\
\text { headaches, too. I still get lightheaded and stuff, but the headaches have subsided dramatically." } \\
\text { (PKU-6) }\end{array}$ \\
\hline & Activities inside home & $\begin{array}{l}\text { "Well, I have to put away my formula when it arrives. I guess that's a household chore that wouldn't } \\
\text { be there if I didn't have PKU." (PKU-4) }\end{array}$ \\
\hline & Sports and recreational activities & $\begin{array}{l}\text { "I had to stop going to Taekwondo for like a month while I gained weight. So that impacted it. I } \\
\text { think exercise definitely impacts it because then I get hungry because my blood sugar drops and } \\
\text { then I have to figure out what to eat which is a little stressful sometimes." (PKU-4) }\end{array}$ \\
\hline & Financial problems & "And then the cost, the cost of having PKU is definitely—can be a struggle." (PKU-10) \\
\hline & Daily activities & $\begin{array}{l}\text { “It affects daily life. Like I said, I'm on disability because I can't even hold a job because my } \\
\text { attendance is so affected by my migraines. The last job that I had, I got fired from because of my } \\
\text { forgetfulness." (PKU-1) }\end{array}$ \\
\hline & $\begin{array}{l}\text { Time spent preparing meals and } \\
\text { counting protein }\end{array}$ & "So eating just takes a longer time, and food preparation takes a longer time." (PKU-10) \\
\hline
\end{tabular}

of the low-protein and medical food, and health insurance issues, were prominent among participants.

Participants reported various social impacts, with many of them $(n=7,70 \%)$ reporting that their ability to perform social activities (e.g., eating out with friends) had been impacted. Spending time to prepare food when going out had an impact on how often participants engaged in activities outside the home. Relationships with family members were also impacted $(n=5,50 \%)$, as mood swings and irritability were often leading to conflicts with family members. Headaches and low energy often affected participants' ability to engage with friends, which could result in relationship breakdowns $(n=3,30 \%)$.

Participants ( $n=3,30 \%)$ also commented on the emotional impacts of the disease, with frustration about disease management and uncertainty about the future (e.g., getting old with PKU) being mentioned. Concerns about pregnancy $(n=2,20 \%)$ (e.g., passing PKU to children) and weight management ( $n=1,10 \%)$ were two physical impacts discussed in relation to PKU.

\section{Contextual Factors (Management of PKU and Treatment Adherence)}

Eight participants described difficulties maintaining low blood Phe levels, and commonly reported difficulties with treatment adherence, including regimen constraints (e.g., not allowed to eat food they liked) $(n=5,63 \%)$, age and peer pressure $(n=4,50 \%$ for each), financial impact $(n=2,25 \%)$, and impact on daily activities and relationships with family members $(n=1,13 \%$ for each). 
Table 4 Summary of spontaneously reported and probed impacts

\begin{tabular}{|c|c|c|c|}
\hline Impact & $\begin{array}{l}\text { Spontaneously reported } \\
n(\%)\end{array}$ & $\begin{array}{l}\text { Probed }^{\mathrm{b}} \\
n(\%)\end{array}$ & $\begin{array}{l}\text { Total report } \\
n(\%)\end{array}$ \\
\hline Ability to travel ${ }^{a}$ & $3(30.0 \%)$ & $6(60.0 \%)$ & $9(90.0 \%)$ \\
\hline Social activities ${ }^{\mathrm{a}}$ & $6(60.0 \%)$ & $1(10.0 \%)$ & $7(70.0 \%)$ \\
\hline Financial impact & $6(60.0 \%)$ & 0 & $6(60.0 \%)$ \\
\hline Work/school activities ${ }^{\mathrm{a}}$ & $5(50.0 \%)$ & 0 & $5(50.0 \%)$ \\
\hline Relationship with family $^{a}$ & $3(30.0 \%)$ & $2(20.0 \%)$ & $5(50.0 \%)$ \\
\hline Daily activities $^{\mathrm{a}}$ & $1(10.0 \%)$ & $4(40.0 \%)$ & $5(50.0 \%)$ \\
\hline Activities outside the home $\mathrm{a}^{\mathrm{a}}$ & $1(10.0 \%)$ & $4(40.0 \%)$ & $5(50.0 \%)$ \\
\hline Positive impacts & $3(30.0 \%)$ & 0 & $3(30.0 \%)$ \\
\hline Time spent preparing dietary meals ${ }^{a}$ & $2(20.0 \%)$ & $1(10.0 \%)$ & $3(30.0 \%)$ \\
\hline Feelings/emotions ${ }^{\mathrm{a}}$ & $1(10.0 \%)$ & $2(20.0 \%)$ & $3(30.0 \%)$ \\
\hline Driving $^{a}$ & $1(10.0 \%)$ & $2(20.0 \%)$ & $3(30.0 \%)$ \\
\hline Relationship with friends ${ }^{a}$ & 0 & $3(30.0 \%)$ & $3(30.0 \%)$ \\
\hline Time spent counting protein & $2(20.0 \%)$ & 0 & $2(20.0 \%)$ \\
\hline PKU's effect on pregnancy & $2(20.0 \%)$ & 0 & $2(20.0 \%)$ \\
\hline Lack of knowledge of medical professionals & $2(20.0 \%)$ & 0 & $2(20.0 \%)$ \\
\hline Activities inside the home ${ }^{a}$ & 0 & $2(20.0 \%)$ & $2(20.0 \%)$ \\
\hline Sports/recreational activities ${ }^{a}$ & 0 & $2(20.0 \%)$ & $2(20.0 \%)$ \\
\hline Poor access to PKU care & $1(10.0 \%)$ & 0 & $1(10.0 \%)$ \\
\hline $\begin{array}{l}\text { Available PKU recipes and ready meals are not } \\
\text { suitable }\end{array}$ & $1(10.0 \%)$ & 0 & $1(10.0 \%)$ \\
\hline Weight management & $1(10.0 \%)$ & 0 & $1(10.0 \%)$ \\
\hline
\end{tabular}

${ }^{a}$ Impact was specifically probed for during the interviews. Mobility was also a probed impact, but no participants reported this either spontaneously or probed; therefore, this impact was not included in the results

${ }^{b}$ If a participant mentioned an impact spontaneously before probing and talked about it after probing, the mention was counted as spontaneous only

\section{Cognitive Interviews}

During the cognitive part of the interviews, participants $(n=10)$ provided feedback on the clarity, relevance, and completeness of the PKUSSIS items; response options and recall period were collected. Overall, no more than a single participant misinterpreted any item on the instrument. Further, no more than one participant indicated an item was difficult to respond to other than an item regarding dietary control of Phe levels. The majority of participants $(n=9)$ indicated the items were relevant. However, a few items were indicated as unimportant; items described as unimportant by more than a single participant were the following: being late for an appointment; misplacing everyday items; waking during the 
night; feeling "jumpy" or "on-edge"; can't sit still.

Four participants indicated that there may be dimensions missing, including questions related to medical institutions, insurance companies, physical coordination or dexterity, feelings about medical foods, tremors, or gastrointestinal issues. All participants asked indicated that they were able to respond to each item on the scale provided. The recall periods used by participants generally followed the prescribed 1 -week time frame. However, one or two participants used a different time frame on each item.

Discussions between members of the study team ensured that key PKU symptoms and impacts were retained and consensus was reached. Seven items found to be redundant, or irrelevant or not important to patients, were removed: taking medical food as prescribed; losing temper; waking up at night; feeling "jumpy" or "on-edge"; worried about money; can't sit still; and maintaining a diet that keeps Phe within the prescribed levels. On the basis of the conceptual model, five items were added to improve the content validity of the instrument in patients with PKU: difficulty staying asleep; difficulty falling asleep; headaches; problems with short-term memory; and skin problems. Fifteen items were revised to improve clarity. The final instrument included 22 items, covering three symptom domains: (1) emotional, mood, and psychological; (2) (neuro)cognitive, executive and intellectual function; and (3) physical. Four impact domains were also covered: (1) social relations; (2) level of independence; (3) general well-being, and (4) self-care.

\section{PKU-SSIS Scores}

Thirty participants completed the draft PKUSSIS. Table 5 presents participants' domains and total scores, with higher scores indicating more severe symptoms. On all domains participants' mean score was below the midpoint of the maximum possible score range (midpoint $=50$; range $=0-100)$; similarly, participants' mean (SD) total score 40.64 (18.03) was also below the midpoint, indicating that participants
Table 5 Domains and total scores for PKU Symptom Severity and Impacts Scale

\begin{tabular}{|c|c|}
\hline Domains & Scores \\
\hline \multicolumn{2}{|c|}{ Emotional, mood and psychological } \\
\hline$n$ (missing) & $30(0)$ \\
\hline Mean (SD) & $42.92(25.09)$ \\
\hline Median & 37.5 \\
\hline Min-max & $6.25-100.00$ \\
\hline \multicolumn{2}{|c|}{ Cognitive, executive and intellectual function } \\
\hline$n$ (missing) & $30(0)$ \\
\hline Mean (SD) & $41.19(18.59)$ \\
\hline Median & 39.29 \\
\hline Min-max & $10.71-85.71$ \\
\hline \multicolumn{2}{|l|}{ Behavior } \\
\hline$n$ (missing) & $30(0)$ \\
\hline Mean $(S D)$ & $31.67(22.68)$ \\
\hline Median & 25 \\
\hline Min-max & $0-100.00$ \\
\hline \multicolumn{2}{|l|}{ Physical } \\
\hline$n$ (missing) & $30(0)$ \\
\hline Mean (SD) & $45.21(26.45)$ \\
\hline Median & 34.38 \\
\hline Min-max & $6.25-100.00$ \\
\hline \multicolumn{2}{|c|}{ General well-being } \\
\hline$n$ (missing) & $30(0)$ \\
\hline Mean (SD) & $41.67(23.57)$ \\
\hline Median & 41.67 \\
\hline Min-max & $0-91.67$ \\
\hline \multicolumn{2}{|l|}{ Self-care } \\
\hline$n$ (missing) & $30(0)$ \\
\hline Mean $(S D)$ & $36.60(18.89)$ \\
\hline Median & 37.5 \\
\hline Min-max & $6.25-75.00$ \\
\hline \multicolumn{2}{|l|}{ Total score } \\
\hline$n$ (missing) & $30(0)$ \\
\hline
\end{tabular}


Table 5 continued

\begin{tabular}{ll}
\hline Domains & Scores \\
\hline Mean (SD) & $40.64(18.03)$ \\
Median & 34.38 \\
Min-max & $14.58-86.46$ \\
\hline
\end{tabular}

$S D$ standard deviation

experienced moderate PKU symptoms severity at the time of the study. Overall participants' responses to the items included in the instrument were equally distributed among the available response options. No indication of floor or ceiling effects was observed for any of the items in the instrument.

\section{DISCUSSION}

This article describes the development and content validation of a disease-specific PRO instrument for patients with PKU to measure symptom severity and impact of PKU on HRQoL, with a particular focus on neuropsychological symptoms and associated impacts. The concept elicitation interviews identified many concepts relevant to capturing a wide range of PKU symptoms and impacts on patients' HRQoL. A few of these concepts have not been assessed with use of generic PRO tools (e.g., skin problems, headaches, insomnia), highlighting both the value of direct contact with patients to fully understand patient experiences with those symptoms and impacts reported to be attributed to having PKU, and of a disease-specific PRO instrument that is able to assess the spectrum of symptoms and impacts experienced by patients. Participants experienced a number of signs and symptoms, spontaneously reporting 24 different concepts; 27 when probed concepts are included. The large number of symptoms confirms the heterogeneity of neuropsychologic symptomatology reported elsewhere [32].

Our findings provide further evidence that, in addition to the direct effects on neuropsychological function, PKU symptoms also impact and interfere with patients' social function, physical health, and emotions, as well as perceived levels of independence. Patients with PKU often cannot perform or avoid performing activities and tasks that those without PKU may take for granted (e.g., meeting with friends for dinner or ability to travel, or performing sports and recreational activities). Ability to travel was the most frequent and bothersome reported impact, followed by social activities demonstrating the impact of PKU on patients' HRQoL.

The draft PKU-SSIS was an instrument that participants found to be relevant to their condition and easy to understand and complete. Additionally, participants did not report any difficulties with the recall period and response options. However, participants commented that a few items (e.g., "maintained diet for Phe levels", "worried about money") were relevant but not important to patients with PKU.

The analysis of the refined conceptual model revealed that some neuropsychological and physical health concepts that were relevant for patients with PKU were not covered in the instrument, such as headaches, tremors, skin problems, short-term memory, insomnia, and thinking clearly and remembering. Therefore, the draft PKU-SSIS was modified to further enhance its relevance, validity, ease of use, and clarity of items in patients with PKU. On the basis of the data collected in this study, the PKU-SSIS is an appropriate, content-validated instrument to include in clinical studies with patients with PKU. A key strength of the PKUSSIS is that it was developed specifically with patients and also clinicians with patients with PKU in mind, and focuses mainly on neuropsychological symptoms and impacts, which are a major concern for this patient population. In contrast, existing disease-specific PRO instruments have a wider focus, risking not adequately capturing important PKU symptoms and impacts. The PKU-SSIS could complement other disease-specific instruments, such as the PKU-QoL (focused on diet management) [13], potentially assisting with a more nuanced evaluation of treatment benefit in patients with ETPKU.

Given the supportive evidence for the content validity of the PKU-SSIS, future studies should be conducted in order to further 
investigate the psychometric properties of the instrument, including the association of change in PKU-SSIS scores with change in Phe levels, and the application of the instrument within clinical research studies. Moreover, performance of the instrument in individuals on dual therapy (i.e., both on diet and treatment, such as sapropterin and/or pegvaliase) would be useful and would allow evaluation of changes in HRQoL in this specific population group.

Overall, the study recruited a diverse sample, in terms of gender, employment, marital status, and educational qualifications. Assessment of saturation of major symptoms and impacts indicated that the sample size can be considered adequate for the purposes of this study.

The study has some limitations. Even though the study implemented a priori eligibility criteria, many participants reported comorbid disorders (e.g., depression, hypertension); hence, it is possible that some of the reported symptoms might be confounded by the presence of such comorbid disorders. However, recent research suggests that some of these comorbidities may likely be attributed to their PKU [33]. This sample population may be somewhat biased as they are all members of a patient association and voluntary self-referral participants. The sample population was predominantly white; therefore, the findings may not be applicable and relevant to people coming from different racial and ethnic backgrounds. However, it should be noted that the incidence of PKU is higher in Caucasian populations than African Americans or Asians [34]. Two adolescents took part in the quantitative survey study, and none in the qualitative study; hence, content validity was established only for adult patients.

\section{CONCLUSION}

This study aimed to examine the content validity of a disease-specific PKU symptoms and impacts PRO instrument, the first that focuses mainly on neuropsychological symptoms and impacts of the disorder (i.e., how PKU affects patients' lives). Even though the measurement properties of the new instrument have not yet been tested extensively, the PKU-SSIS has the potential to address an important gap in the evaluation of existing and future treatments for PKU. The PKU-SSIS is equally applicable to clinical or real-world studies, as well as in clinical practice, and will enhance the understanding of the factors that may influence the symptoms and impacts of PKU and help clinical teams to monitor the efficacy/effectiveness of existing and new pharmacological interventions.

\section{ACKNOWLEDGEMENTS}

The authors would like to thank all of the patients who took part in this research and to the National Phenylketonuria Alliance (NPKUA) for partnering with us on patient recruitment. Many thanks to Beverly Romero, Christina O'Donnell and Kelly Lipman for conducting patient interviews, Ryan Murphy for assisting with data analysis and study conduct, Meg Leary for her operational support, and Beverly Romero for her review and advice on instrument revisions and data interpretation.

Funding. This study and manuscript development, including the journal's Rapid Service and Open Access Fees, were fully funded by BioMarin Europe Ltd.

Authorship. All named authors meet the International Committee of Medical Journal Editors (ICMJE) criteria for authorship for this article, take responsibility for the integrity of the work as a whole, and have given their approval for this version to be published.

Author Contributions. Jennifer Quinn and Elaina Jurecki developed the draft instrument, study protocol, and finalized instrument, and critically revised the manuscript. Alexandros Georgiadis and Hannah B. Lewis developed the study protocol and the finalized instrument, oversaw data collection and analysis, interpreted the results, and drafted the manuscript.

Disclosures. Jennifer Quinn and Elaina Jurecki are employees and stockholders of 
BioMarin. Hannah B. Lewis is an employee of ICON. Alexandros Georgiadis was an employee of ICON at the time of the study, and is now an employee of Pfizer Ltd.

Compliance with Ethics Guidelines. Approval was obtained from Salus Institutional Review Board (Austin, TX, USA). The procedures used in this study adhere to the tenets of the Declaration of Helsinki. Informed consent was obtained from all individual participants included in the study. For adolescent participants, informed consent was obtained from a parent and informed assent was obtained from the participant. Informed consent documents explained that anonymised study results may be used in scientific publications.

Data Availability. The de-identified individual participant data that underlie the results reported in this article may be made available together with the research protocol and data dictionaries, for non-commercial, academic purposes. Additional supporting documents may be available beginning 6 months and ending 2 years after publication. Research proposals will be evaluated relative to publicly available criteria on the BioMarin Data Sharing Web Page at www.BioMarin.com/patients/publicationdata-request/ to determine if access will be given, contingent upon execution of a data access agreement with BioMarin Pharmaceutical Inc.

Open Access. This article is licensed under a Creative Commons Attribution-NonCommercial 4.0 International License, which permits any non-commercial use, sharing, adaptation, distribution and reproduction in any medium or format, as long as you give appropriate credit to the original author(s) and the source, provide a link to the Creative Commons licence, and indicate if changes were made. The images or other third party material in this article are included in the article's Creative Commons licence, unless indicated otherwise in a credit line to the material. If material is not included in the article's Creative Commons licence and your intended use is not permitted by statutory regulation or exceeds the permitted use, you will need to obtain permission directly from the copyright holder. To view a copy of this licence, visit http:// creativecommons.org/licenses/by-nc/4.0/.

\section{REFERENCES}

1. Scriver CR, Levy H, Donlon J. Hyperphenylalaninemia: phenylalanine hydroxylase deficiency. In: Valle D, Beaudet AL, Vogelstein B, Kinzler KW, Antonarakis SE, Ballabio A, editors. The online metabolic and molecular bases of inherited disease. McGraw Hill Medical; 2008. http://www.ommbid. com. Accessed 14 Dec 2019.

2. Paine RS. The variability in manifestations of untreated patients with phenylketonuria (phenylpyruvic aciduria). Pediatrics. 1957;20: 290-302.

3. Waisbren SE, Noel K, Fahrbach K, et al. Phenylalanine blood levels and clinical outcomes in phenylketonuria: a systematic literature review and meta-analysis. Mol Genet Metab. 2007;92(1-2): 63-70.

4. Guthrie R, Susi A. A simple phenylalanine method for detecting phenylketonuria in large populations of newborn infants. Pediatrics. 1963;32:338-43.

5. Alfadhel M, Al Othaim A, Al Saif S, et al. Expanded newborn screening program in Saudi Arabia: incidence of screened disorders. J Paediatr Child Health. 2017;53(6):585-91.

6. Blau N, Bélanger-Quintana A, Demirkol $\mathrm{M}$, et al. Management of phenylketonuria in Europe: survey results from 19 countries. Mol Genet Metab. 2010;99(2):109-15.

7. Cazzorla C, Bensi G, Biasucci G, et al. Living with phenylketonuria in adulthood: the PKU ATTITUDE study. Mol Genet Metab Rep. 2008;16:39-45.

8. National Institutes of Health Consensus Development Panel. National Institutes of Health Consensus Development Conference Statement: phenylketonuria: screening and management, October 16-18, 2000. Pediatrics. 2001;108(4): 972-82.

9. Guest JF, Bai JJ, Taylor RR, Sladkevicius E, Lee PJ, Lachmann RH. Costs and outcomes over 36 years of patients with phenylketonuria who do and do not remain on a phenylalanine-restricted diet. J Intellect Disabil Res. 2013;57(6):567-79. 
10. Poustie VJ, Rutherford P. Dietary interventions for phenylketonuria. Cochrane Database Syst Rev. 2000;2:CD001304.

11. Thomas J, Nguyen-Driver M, Bausell H, Breck J, Zambrano J, Birardi V. Strategies for successful longterm engagement of adults with phenylalanine hydroxylase deficiency returning to the clinic. J Inborn Errors Metab Screen. 2017;5:1-9.

12. Berry SA, Brown C, Grant $M$, et al. Newborn screening 50 years later: access issues faced by adults with PKU. Genet Med. 2013;15(8):591-9.

13. Regnault A, Burlina A, Cunningham A. Development and psychometric validation of measures to assess the impact of phenylketonuria and its dietary treatment on patients' and parents' quality of life: the phenylketonuria - quality of life (PKU-QOL) questionnaires. Orphanet J Rare Dis. 2015. https:// doi.org/10.1186/s13023-015-0261-6.

14. Thomas J, Levy H, Amato S, et al. Pegvaliase for the treatment of phenylketonuria: results of a longterm phase 3 clinical trial program (PRISM). Mol Genet Metab. 2018;124(1):27-38.

15. Jurecki ER, Cederbaum S, Kopesky J, et al. Adherence to clinic recommendations among patients with phenylketonuria in the United States. Mol Genet Metab. 2017;120(3):190-7.

16. Ahring K, Belanger-Quintana A, Dokoupil K, et al. Blood phenylalanine control in phenylketonuria: $\mathrm{a}$ survey of 10 European centres. Eur J Clin Nutr. $2011 ; 65(2): 275-8$.

17. Bilder DA, Noel JK, Baker ER, et al. Systematic review and meta-analysis of neuropsychiatric symptoms and executive functioning in adults with phenylketonuria. Dev Neuropsychol. 2016;41(4): 245-60.

18. Simon E, Schwarz M, Roos J, et al. Evaluation of quality of life and description of the sociodemographic state of adolescent and young adult patients with phenylketonuria. Health Qual Life Outcomes. 2008;6:25.

19. Koch R, Burton B, Hoganson G, et al. Phenylketonuria in adulthood: a collaborative study. J Inherit Metab Dis. 2002;25:333-46.

20. Beckhauser MT, Beghini MVM, Moehlecke Iser B, et al. Attention deficit disorder with hyperactivity symptoms in early-treated PKU patients. Iran J Child Neurol. 2020;14(1):93-103.

21. Gassio R, Campistol J, Vilaseca MA, Lambruschini N, Cambra FJ, Fuste E. Do adult patients with phenylketonuria improve their quality of life after introduction/resumption of a phenylalanine-restricted diet? Acta Paediatr. 2003;92:1474-8.

22. Bik-Multanowski M, Didycz B, Mozrzymas R, et al. Quality of life in noncompliant adults with phenylketonuria after resumption of the diet. J Inherit Metab Dis. 2008;31(Suppl 2):S415-8.

23. Alptekin IM, Koc N, Gunduz M, Cakirogly FP. The impact of phenylketonuria on PKU patients' quality of life: using of the phenylketonuria-quality of life (PKU-QOL) questionnaires. Clin Nutr ESPEN. 2018;27:79-85.

24. Lasch KE, Marqis P, Vigneux M, et al. PRO development: rigorous qualitative research as the crucial foundation. Qual Life Res. 2010;19(8):1087-96.

25. US Food and Drug Administration. Guidance for industry: Patient reported outcome measures: use in medicinal product development to support labelling claims. 2009 Dec. https://www.fda.gov/ regulatory-information/search-fda-guidancedocuments/patient-reported-outcome-measuresuse-medical-product-development-supportlabeling-claims. Accessed 28 Aug 2020.

26. Christ SE, Clocksin HE, Burton BK, et al. Executive function in phenylketonuria (PKU): insights from the Behavior Rating Inventory of Executive Function (BRIEF) and a large sample of individuals with PKU. Neuropsychology. 2020;34(4):456-66.

27. Bacci ED, Wyrwich KW, Gries KS, et al. An adaptation of the Profile of Mood States for use in adults with phenylketonuria. J Inborn Errors Metab Screen. 2016;4:1-11.

28. Douglas TD, Ramakrishnan U, Kable JA, Singh RH. Longitudinal quality of life analysis in a phenylketonuria cohort provided sapropterin dihydrochloride. Health Qual Life Outcomes. 2013;11:218.

29. US Food and Drug Administration. CDER PatientFocused Drug Development. https://www.fda.gov/ drugs/development-approval-process-drugs/cderpatient-focused-drug-development. Accessed 28 Aug 2020.

30. Joffe H, Yardley L. Content and thematic analysis. In: Marks DF, Yardley L, editors. Research methods for clinical and health psychology. London: SAGE; 2013. p. 56-68.

31. Kerr C, Nixon A, Wild D. Assessing and demonstrating data saturation in qualitative inquire supporting patient-reported outcomes research. Expert Rev Pharmacoecon Outcomes Res. 2010;10(3): 269-81.

32. Ashe K, Kelso W, Farrand S, et al. Psychiatric and cognitive aspects of phenylketonuria: the 
limitation of diet and promise of new treatments. Front Psychiatry. 2019;10:561.

33. Burton BK, Jones BK, Cederbaum S, et al. Prevalence of comorbid conditions among adult patients diagnosed with phenylketonuria. Mol Genet Metab. 2018;125(3):228-34.
34. Talkowski ME, McClain L, Allen T, et al. Convergent patterns of association between phenylalanine hydroxylase variants and schizophrenia in four independent samples. Am J Med Genet B Neuropsychiatr Genet. 2009;150(4):560-9. 